\title{
LA INVIOLABILIDAD REGIA EN PERSPECTIVA COMPARADA: REVISIÓN HISTÓRICA E INTERPRETACIONES CONTEMPORÁNEAS
}

\author{
LEIRE ESCAJEDO SAN-EPIFANIO \\ Profesora Titular de Derecho Constitucional \\ Universidad del País Vasco (UPV/EHU) ${ }^{1}$
}

TRC, núm. 46, 2020, pp. 403-430

ISSN 1139-5583

SUMARIO

I. La inviolabilidad regia, ¿cuestión constitucional en el siglo XxI? II. Parámetros clave para abordar la inviolabilidad regia: tesis de la contraprestación, disonancia democrática y mitos constitucionales. III. La inviolabilidad regia, jes un factor de refuerzo o, por el contrario, un talón de Aquiles para la continuidad de una monarquía? IV. Reconocida la inviolabilidad, ¿es posible juzgar al monarca? dos juicios históricos y algunas notas contemporáneas. V. La difícil supervivencia de las democracias coronadas en el siglo XXI: imposible sin unas mínimas reformas.

\section{LA INVIOLABILIDAD REGIA, ¿CUESTIÓN CONSTITUCIONAL EN EL SIGLO XXI?}

Dejando al margen la atención que merece en los manuales y tratados del área, la Monarquía Parlamentaria y, dentro de ella, los estatutos regios han sido cuestiones a las que la doctrina jurídico-constitucional ha prestado una atención más bien puntual, en torno a situaciones de especial tensión en algún reinado o proceso de sucesión. Todos esos momentos, por cuanto se refiere al debate político y doctrinal, suelen tener una particularidad en común, y es que reabren, por así decirlo, una duda —en apariencia aún no resuelta — que en casos como el de Inglaterra viene a remontarse nada más y nada menos que al siglo XIII: ¿es la Ley la que hace al Rey, o se es ya Rey — y se tiene un estatuto- antes de que una Constitución así lo establezca? Desde

1 Miembro del Grupo de Investigación del Sistema Universitario Vasco IT-1380/19, Gobernanza Multinivel y Derecho Europeo - Multilevel Governance and EU Law, IP A. LóPEZ BASAGUREN. 
la racionalidad jurídica y argumentando desde los principios que sostienen las constituciones democráticas, pareciera que poca duda cabe a este respecto. Pero tal y como se ha podido comprobar recientemente en España, este debate sobre la inviolabilidad parece tener aún plena vigencia. Desde que Juan Carlos I de Borbón abdicase en su hijo, Felipe VI, se han vivido varios acontecimientos. Primero decidió dejar la vida pública y, recientemente, ha decidido trasladar su residencia al extranjero, en teoría — y según reza su comunicado- para brindar a su sucesor la «tranquilidad y sosiego» que necesita el ejercicio de la Jefatura de Estado.

Publicada menos de un mes después de la Ley Orgánica de abdicación de Juan Carlos $\mathrm{I}^{2}$, la L.O. 4/2014³ incorporó a la Ley Orgánica del Poder Judicial un artículo 55 bis, reconociendo el aforamiento, entre otros, del Rey que bubiere abdicado y de su consorte. Lo más llamativo de esta L.O., sin embargo, no fue que clarificase posibles escenarios procesales respecto al rey emérito, sino que en su Preámbulo tuviera la llamativa pretensión de precisar el modo en que, en su caso, habría de interpretarse la inviolabilidad regia recogida en la Constitución Española de 1978. Así, el apartado IV del Preámbulo de dicha L.O expresa que «la figura del Rey está constitucionalmente revestida de la inviolabilidad e inmunidad que tanto los antecedentes históricos como el derecho comparado atribuyen al Jefe de Estado", y añade que de conformidad con el artículo 56.3 CE «todos los actos realizados por el Rey o la Reina durante el tiempo en que ostentare la jefatura del Estado, cualquiera que fuere su naturaleza, quedan amparados por la inviolabilidad y están exentos de responsabilidad». La amplitud con la que aquí se describe la inviolabilidad regia, no tiene, sin embargo, un amparo tan rotundo en los antecedentes históricos o en el Derecho comparado ni, dicho sea de paso, en el sistema constitucional vigente en España. Cierto es que el Tribunal Constitucional viene reconociendo que los preámbulos pueden llegar a tener un importante valor hermenéutico, por ejemplo a la hora de interpretar conceptos indeterminados, pero ello no ha de leerse en el sentido de que, de algún modo, se les termina reconociendo valor normativo ${ }^{4,5}$. En el caso que nos ocupa, además, no se trata de precisar conceptos indeterminados recogidos en alguna ley, sino que la pretensión del preámbulo parece ser la de influir nada más y nada menos que en la interpretación del artículo 56.3 CE. Por más que políticamente comprensible, jurídicamente se trata de una pretensión poco acertada.

Sin eludir ese contexto, el presente trabajo aborda un estudio histórico y contemporáneo de la inviolabilidad regia en el Derecho comparado. Las conclusiones de este análisis se presentan en varios bloques, comenzando con un primer bloque en el

2 Publicada en BOE n. ${ }^{\circ} 148$, de 19 de junio de 2014.

3 L.O. 4/2014, de 11 de julio, complementaria de la Ley de racionalización del sector público y otras medidas de reforma administrativa por la que se modifica la L.O. 6/1985, de 1 de julio, del Poder Judicial.

4 FJ de la STC 36/81, de 12 de noviembre y STC 150/ 1990, de 4 de octubre.

5 Sentencia de 9 de mayo de 2011, Sección 7. a de la Sala de lo Contencioso-Administrativo del Tribunal Supremo, Recurso de Casación n. ${ }^{0}$ 1962/2009, confirmando la Sentencia n. ${ }^{\circ}$ 73/2009 de 27 enero, del TSJ de Justicia de la Comunidad Valenciana. 
que se tratan tres parámetros clave en el abordaje de la inviolabilidad regia, toda vez que en ellos se aprecia en profundidad el calado de debates que, por más que históricos, siguen de algún modo vivos en la actualidad. Tales parámetros son, en primer lugar, el relato de la inviolabilidad como contraprestación y, en segundo lugar, la gestión de la disonancia democrática que representa la monarquía. A ellos se suma, como tercer parámetro, el peso que tienen los mitos fundacionales en todo sistema constitucional y, especialmente, en las llamadas democracias coronadas, término al que volveremos con más detalle. En un segundo bloque de atención se prestará atención a la cuestión de si la inviolabilidad regia, en la práctica, es realmente un factor de refuerzo de los Jefes de Estado en las Monarquías o si, por el contrario, tiene más un perfil de Talón de Aquiles para su continuidad. En tercer y último lugar, y tras un minucioso estudio histórico-jurídico, se abordará de forma singular la cuestión de si reconocida la inviolabilidad es (o no) posible juzgar al monarca. Los juicios históricos a Carlos Estuardo de Inglaterra y a Louis XVI de Francia, ambos en sede parlamentaria, resultan de interés en esa reflexión, si bien los hechos juzgados en aquel tiempo (básicamente traiciones a la nación), difieren significativamente de la tipología de asuntos que en nuestro tiempo vienen abriendo debates en torno a la inviolabilidad regia (como es el caso de las demandas de paternidad o, especialmente, las irregularidades en la gestión, sobre todo fiscal, de los patrimonios privados).

\section{PARÁMETROS CLAVE PARA ABORDAR LA INVIOLABILIDAD REGIA: TESIS DE LA CONTRAPRESTACIÓN, DISONANCIA DEMOCRÁTICA Y MITOS CONSTITUCIONALES}

En 1791, en la Asamblea Constituyente francesa, Robespierre interpelaba a la cámara con un discurso que, con la cautela que merecen los enfoques presentistas ${ }^{6}$, mantiene un algunos tintes rastreables desde entonces hasta nuestro tiempo: «Es a vosotros a quienes pregunto, a vosotros que sostenéis ese sistema tan enérgicamente: si un rey degollase a vuestro bijo en vuestra presencia, si ultrajase a vuestra mujer o a vuestra bija, ¿le diríais acaso: Sire, estáis en vuestro derecho, os hemos permitido todo?". Con una retórica que claramente apela al pathos ${ }^{7}$, intentaba Robespierre que su audiencia visualizase el elevado coste que, en casos concretos, se pudiera llegar a pagar como contraprestación de una inviolabilidad reconocida a quien, por más que monarca, no por ello dejaba de ser un hombre más ${ }^{8}$.

6 Dean, M., Critical and Effective Histories: Foucault's Methods and Historical Sociology, Routledge, New York, 1994; OwEN, D., «Genealogy as Exemplary Critique: Reflections on Foucault and the Imagination of the Political», Economy and Society, 24 (4), 1995, pp. 489-506. Vid. también Wilson, N. J., History in Crisis? Recent Directions in Historiography, Prentice-Hall, Upper Saddle River, New Jersey, 1999.

7 Rubinelli, S., «Logos and pathos in Aristotle's Rhetoric. A journey into the role of emotions in rational persuasion in rhetoric», Revue internationale de philosophie, 2018, 286 (4), pp. 361-374.

8 Ariely, D., Predictably Irrational: The Hidden Forces that Shape Our Decisions, Harper Collins, Nueva York, 2008. 


\section{El relato de la inviolabilidad como contraprestación}

Visualizando la escena antes descrita, conviene ahora detenerse un momento en que, con esa apelación al coste, Robespierre parece aceptar una premisa del discurso contrario. Nos referimos a esa idea de que la inviolabilidad, junto con otras prerrogativas, es una especie de pago o un tributo con el que se persigue compensar a quien renuncia — con su encaje constitucional - a un poder que fuera por estirpe, por naturaleza o por voluntad de Dios parece ser que ya tuviera antes del momento constituyente. Los defensores de la inviolabilidad, como puede comprobarse en otros discursos de la época, sostenían que ser excusado de responder por sus actos ante las autoridades terrenales parecía una contraprestación mínima por el alto coste de renunciar a un poder que, ya antes de la Ley, correspondía al Monarca. $\mathrm{Y}$ al entrar a debatir si esa contraprestación es mínima o excesiva, quienes se oponen a la inviolabilidad o, al menos, a sus interpretaciones más extremas, no parecen darse cuenta de que están dando por buena la base de ese razonamiento.

Podemos rastrear versiones similares de este discurso de la contraprestación en razonamientos que apelan a la inviolabilidad como reconocimiento de legados históricos o tributos - ya sean familiares, ya de personas concretas de una dinastía - o de lo que supone vivir en la ejemplaridad ${ }^{9}$, puesto que sea más o menos elevado aquello que se reconoce como específico de un monarca o de una familia real, en todos estos relatos el acomodo regio en las Constituciones parece interpretarse como expresión de un pueblo, una ciudadanía, que explícita o implícitamente se reconoce deudora (aunque lo sea en términos morales) en el momento constituyente. Con todo, parece que la tesis de la contraprestación sólo excusaría la totalidad de los actos regios — incluyendo los de naturaleza privada — si es llevada hasta el extremo, porque equilibrando esa idea de la contraprestación con un objetivo de protección de la institución de la Corona sólo cabría excusar los actos regios en sentido estricto ${ }^{10}$.

\section{La disonancia democrática inherente a las Monarquías Parlamentarias}

Explicó magistralmente Festinger que los individuos - y las colectividades- tienen una fuerte necesidad de que sus creencias, actitudes y decisiones o conductas sean coherentes entre sí; una necesidad de vivir, como él dice, en consonancia cognitiva ${ }^{11}$. Lejos, sin embargo, de que esto lleve a las personas y colectividades a ajustar sus actitudes y conductas de modo que sean coherentes con sus

9 Palacios Bañuelos, L. «La Monarquía española: del «Juancarlismo» a Felipe VI», La Albolafia: Revista de Humanidades y Cultura, 5, 2015, pp. 191-208.

10 De Vega García, P.: "Constitución y Democracia, en López Pina (ed.), La Constitución de la Monarquía Parlamentaria, FCE, México, 1983, pp. 68 y ss.

11 Festinger, L., Theory of Cognitive Dissonance, 1957 y «Cognitive Dissonance», Scientific American, 1962, 204(4), pp. 93-106. 
valores y principios, lo cierto es que entre las opciones más recurrentes y cómodas para gestionar las posibles disonancias cognitivas están el autoengaño, el encubrimiento o disimulo de las contradicciones o, como mínimo, un intento por justificarlas para evitar que puedan quedar en evidencia ${ }^{12}$. Desde una perspectiva colectiva, vemos esta afirmación cercana a la que emplea Weber ${ }^{13}$ cuando dice que, en principio, la fuerza de la conservación es más poderosa y está en condiciones favorables de prevalecer frente a su contraria (o fuerza disidente). La soberanía nacional, reza el artículo 1 de la Constitución Española, reside en el pueblo español, del que emanan los poderes del Estado, y tanto los ciudadanos como los poderes públicos están sujetos a la Constitución y al resto del ordenamiento jurídico (art. 9.1), garantizando la Constitución, entre otras cosas, la legalidad, la responsabilidad y la interdicción de la arbitrariedad de los poderes públicos (9.3 CE). Ni como ciudadano ni como poder público cabe defender del Rey o Reina, por más que el artículo $56 \mathrm{CE}$ así parezca darlo a entender, que estas personas puedan eludir tales sujeciones. Planteado incluso en la órbita de la ambigua idea de la ejemplaridad, ¿acaso hay algo más ejemplar que estar sujeto al mismo ordenamiento que el resto de los ciudadanos? Reiteradamente, incluso en prólogos de Leyes Orgánicas como la citada al comienzo de este trabajo, hay una cierta tendencia a defender que las reglas interpretativas que dan lógica y unidad al sistema pueden excepcionarse cuando se trata de interpretar la inviolabilidad regia. Nótese, sin embargo, que fórmulas de interpretación similares serían fuertemente contestadas respecto de la inviolabilidad que el artículo 10 reconoce a los derechos inherentes a la persona. Tal inviolabilidad debe necesariamente ser interpretada como parte de un sistema, a pesar de la rotundidad con la que se reconocen su indiscutible superioridad axiológica en el Estado constitucional, y su intangibilidad absoluta por parte tanto de los poderes públicos como de los ciudadanos ${ }^{14}$. Si bien se interpreta que ese carácter impide requerir sacrificios innecesarios o desproporcionados de estos derechos, o un desaliento en su ejercicio, sabido es también que no por ello se les reconoce un carácter de absolutos ni ilimitado ${ }^{15}$.

Desde estos parámetros cabe contemplar, en nuestra opinión, el modo en que las democracias coronadas —en expresión de Alzaga Villaamil ${ }^{16}$ — tienden a elu-

12 Beasley, R.K./ Joslyn, M.R., «Cognitive Dissonance and Post-Decision Attitude Change in Six Presidential Elections», Political Psychology, 2001, 22(3): pp. 521-540; LADA, A., «Cognitive Dissonance and the Success of Democracy», Social Science Research Network (SSRN)-Elsevier, 2009, http://dx.doi. org/10.2139/ssrn.1345417.

13 Weber, M., Economía y Sociedad, FCE, México, 1964.

14 Con detalladas referencias doctrinales, tanto a la doctrina española como a la italiana, vid. GAVARA De CARA, J. C., La proyección interna de la dimensión objetiva de los derechos fundamentales: el artículo 10.1 CE, JM Bosch, 2011.

15 Vid., entre otras, STC 2/1982 FJ 5, STC 116/1984 FJ 5, STC 1996/ 2006 FJ 6, STC 124/2005 FJ 3, STC 110/2006 FJ4, STC 108/2008 FJ3.

16 Alzaga Villaamil, O., «Intervención en la Comisión de Asuntos Constitucionales y Libertades Públicas», Diario de Sesiones del Congreso de los Diputados, 11 de mayo de 1978, pp. 2205-2217 (consultada la versión publicada en Alzaga Vilaamil, O., Discursos parlamentarios (y otras disertaciones), Marcial Pons Fundación CC, Madrid), 2019. 
dir con insistencia adentrarse en la discordancia que genera mantener un Jefe de Estado monárquico en un sistema democrático. La Corona, dirán en el Reino Unido, se sostiene en una serie de elementos emotivos que «no siempre se comprenden» ${ }^{17}$ o, más contundente, se llegará a decir en el XIX en Bélgica que es por deseo del pueblo que la monarquía se sostiene sobre dos ficciones políticas (la heredabilidad y la inviolabilidad $)^{18}$, y que se sostendrá en tanto el pueblo así lo siga deseando. Si, como acabamos de ver, se acepta la disonancia mayor, esto es, la que se evidencia en el difícil (o imposible) acomodo regio a la racionalidad democrática, es comprensible que sobre justificaciones similares se eluda abordar aquellas disonancias - mucho menores - que puedan referirse, por ejemplo, a lo que es 0 no exigible y esperable de un monarca en democracia, ya como Jefe de Estado ya en su actuación privada. En esa ficción atemporal sobre el estatuto regio se mantiene el Preámbulo con el que abríamos este trabajo, al decir genéricamente que la inviolabilidad e inmunidad está revestida de algo que «los antecedentes históricos y el Derecho comparado» atribuyen al Rey de España, y pasar por alto que, por razones obvias y como veremos con más detalle, muy pocas de las monarquías (históricas o comparadas) pueden servir de referente para interpretar el estatuto regio en un sistema democrático. De hecho, y en no pocas ocasiones, se viene reconociendo que la inmunidad soberana en general, sea respecto de cualquier tipo de autoridad, parece una doctrina fácil de atacar y muy difícil de defender en los sistemas democráticos ${ }^{19}$ y que las razones por las que sobrevive, incluso en sistemas no monárquicos como el estadounidense, se cuenta entre los mayores misterios de algunos sistemas comparados ${ }^{20}$.

En pleno siglo XXI compartimos, eso sí, esta peculiar situación con una treintena de países de diferentes continentes ${ }^{21}$, si bien en dieciséis de ellos llamativamente reina la misma persona: Isabel de Windsor ${ }^{22}$. Accedió al trono del

17 Expresión de Sidney Low, citado de la obra The Governance of England (1904), por MCLEAN, en What's wrong with the British Constitution, Oxford University Press, 2010, p.viii, y BonEY, en «Some constitutional issues concerning the installation of the Monarch», British Politics, vo. 7, n. ${ }^{\circ}$ 2, 2012, p. 1641.

18 Deseure, B., "National Sovereignty in the Belgian Constitution of 1831. On the Meaning(s) of Article 25", Reconsidering Constitutional Formation, de la serie Studies in the History of Law and Justice, Springer, 2016, pp. 93 a 157.

19 Con numerosas referencias doctrinales, Seidman, G. I. «The Origins of Accountability: Everything I Know About the Sovereign's Immunity, I Learned From King Henry III». Saint Louis University Law Journal, 2005, vol 49 (2), pp. 393-480.

20 Desan, Ch. A., «The Constitutional Commitment to Legislative Adjudication in the Early American Tradition», 111 Harvard. Law Review, 1998, pp. 1381 y 1383.

21 Junto a los 16 Realms de la Commonwealth, han de contarse entre las monarquías parlamentarias de Bélgica, Dinamarca, España Países Bajos, Noruega y Suecia, junto con el Gran Ducado de Luxemburgo, los principados de Andorra, Liechtenstein y Mónaco y, desde los Pactos de Letrán de 1929, el Vaticano; en otros continentes encontramos monarquías en países como Bahréin, Lesoto, Jordania, Camboya, Malasia o Japón.

22 El Reino Unido de la Gran Bretaña, cinco países de Oceanía (Nueva Zelanda, Australia, Papúa Nueva Guinea, Islas Salomón y Tuvalú) y diez países del continente americano (Canadá y los estados de Antigua y Barbuda, Bahamas, Barbados, Belice, Granada, Jamaica, San Cristóbal y Nieves, Santa Lucía y San Vicente y las Granadinas) tienen en la actualidad como Monarca y Jefa de Estado a la Reina Elizabeth 
Reino Unido de la Gran Bretaña y Norte de Irlanda el 6 de febrero de $1952^{23}$ y en estos momentos, que sigue en activo, es la mujer que por más tiempo ha reinado en la historia. Sólo tres hombres, ninguno de ellos actualmente en el cargo, tuvieron un reinado más dilatado que el suyo: Luis XVI de Francia (1643-1715), Rama IX de Thailandia (1946-2016) y Juan II de Liechtenstein (1858-1929). Esto que pudiera verse como una fortaleza, lo cierto es que genera a su vez una cierta preocupación, ante la posibilidad de que la baja popularidad del actual príncipe de Gales termine por traducir la sucesión en éste en una cascada de reformas hacia la abolición de la monarquía. En el espejo del reinado de Isabel de Windsor, al que sorprendentemente algunas colonias británicas independizadas se han acogido generando lazos nuevos, y en el modo en que en casi siete décadas de reinado ha conseguido afrontar numerosas circunstancias políticas y familiares, se miran muchos de los monarcas de otros países. Y ese boato hace la mayor parte del tiempo innecesario preguntar, en pleno siglo XXI, si es la Ley la que hace el Rey, o el Rey o Reina ya lo son antes incluso de que se apruebe la Constitución que los instituye como tales.

\section{Lo simbólico y lo racional en las democracias coronadas: parámetro tercero del análisis}

En todas las constituciones existe, con mayor o menor medida, lo que Volkmann ${ }^{24}$ denomina «mito fundacional» y que parece servir de base a la construcción de relatos fundacionales, en plural, que no necesariamente son compatibles entre sí. Amplificar o reducir la distancia que, con la nueva creación, con lo constituido, se produce entre lo viejo y lo nuevo, escenificar rupturas y nuevos tiempos o reforzar ideas de continuidad, todo ello son componentes simbólicos a los que de algún modo se busca acomodo en torno al acto constituyente. Así, por ejemplo, es frecuente que los preámbulos constitucionales recojan componentes narrativos en los que se evoca bien el ser puente entre el pasado de una nación y el futuro que ésta anhela ${ }^{25}$, $\mathrm{o}$, por el contrario, el deseo de romper con algunos acontecimientos del pasado para afrontar el futuro. Se idealizan también algunos momentos constituyentes que en la realidad fueron mucho más traumáticos de lo que se recuerda. En todos esos casos, no sólo el acto constituyente sino el propio texto de las Constituciones escri-

Alexandra Mary Windsor. Hasta la década de los 60-70 había sido también monarca de los estados de Ghana, Nigeria, Sierra Leona, Tanganica, Uganda, Kenia, Malawi, Mauricio, Sudáfrica, Gambia, Trinidad y Tobago, Guyana, Pakistán, Ceilán y Malta, hoy en día todos ellos repúblicas, y en 1987 dejó de ser reina de Fiji.

23 Coronada el 2 de junio de 1953.

24 Volkmann, U., «El Derecho Constitucional, entre pretensión normativa y realidad política», Teoría y Realidad Constitucional, 2008, n. ${ }^{\circ} 21,187-217$, pp. 188-189.

25 Véase en este sentido el análisis de KING, J., «Constitutions as mission statements», en D. J. Gallingan/ M. Versteeg, Social and Political Foundations of Constitutions, 2013, p. 82. 
tas — o al menos algunos de sus apartados — terminan siendo utilizados como una suerte de tótem o fetiche ${ }^{26}$.

Al igual que la Revolución Francesa y su Constitución pretendieron, dirá García de Enterría ${ }^{27}$, «nada más y nada menos que rectificar la bistoria entera de la bumanidad, fundar un nuevo orden político y social completamente nuevo», la Transición española también parece fundar de inmediato un orden nuevo, inaugurar una nueva época. Alternativamente, y según el discurso, encontramos quienes ensalzan la figura de Juan Carlos I, en tanto «artífice de esa transición» ${ }^{28}$ o voces políticas que, especialmente en estos tiempos de desprestigio de su persona, ensalzan el «pacto constitucional» ${ }^{29}$, aunque no todas las voces - al menos no en tiempos recientes - entienden que ese reconocimiento deba traducirse en una interpretación absoluta de la inviolabilidad regia. Esas narrativas no eluden, aunque sí perfilan desde ese simbolismo, el hecho de que un Jefe de Estado nombrado sucesor durante el Franquismo fuera reconvertido a Monarca en un régimen democrático $^{30}$ o que ya el Caudillo hubiera dispuesto sobre sí mismo y en el contexto de una Dictadura que «la persona del Jefe de Estado es inviolable» ${ }^{31}$. Llegará a afirmarse que Juan Carlos I ostentó la Corona en virtud de un derecho reconocido (no creado) por la Constitución Española de $1978^{32}$, pero que sus sucesores, en la actualidad Felipe VI, ocuparían ya la Corona según lo previsto en el texto constitucional. Desde una perspectiva jurídico constitucional, sin embargo, parece difícil de defender que esto pueda llegar a traducirse en diferentes interpretaciones de la inviolabilidad de Juan Carlos I respecto a sus sucesores.

En el ámbito comparado cabe comprobar tendencias similares. En Inglaterra, por ejemplo, el paso de los siglos y los cambios de modelos de monarquía, incluso de familia real, no parecen haber afectado a lo que se considera la esencia de esos componentes dignificados a los que nos referíamos. Ello contribuye a reforzar una de las funciones que, de algún modo, se atribuye a la institución monárquica en las democracias contemporáneas y en la que vamos a detenernos ahora: la de simbolizar la unidad y permanencia del Estado. El caso que mejor evidencia esa permanencia

26 En expresión de Max Lerner (1937), citado por Jones, B. C., Constitutional Idolatry and Democracy. Challenging the infatuation with writtenness, Edward Elgar Publishing, 2020, pp. 2-3.

27 García De Enterría, E., La lengua de los derechos. La formación del derecho público europeo tras la Revolución Francesa, Alianza, Madrid, 1994, pp. 47-48.

28 Así, el manifiesto de apoyo que 215 antiguos altos cargos enviaron a finales de agosto de 2020 a la Zarzuela, reivindicando el legado de Juan Carlos I, y del que se hizo eco la prensa escrita.

29 Así, las declaraciones del presidente del gobierno español Pedro Sánchez publicadas el 1 de septiembre de 2020 en la prensa escrita, una vez se dio a conocer el traslado de residencia del Rey emérito al extranjero.

30 Véase Gallego Margaleff, F., El mito de la transición. La crisis del franquismo y los orígenes de la democracia (1973-1977), Ed. Crítica, Barcelona, 2008; Andrè-BazZana, B. Mitos y mentiras de la Transición, Ed. El Viejo Topo, Barcelona, 2006.

31 Artículo 8.1 de la L.O. 1/ 1967 del Estado, publicada en el BOE n. ${ }^{\circ}$ 9, de 11 de enero de 1967, pp. 466 a 477. Vid. De Esteban, J., «La confusa inviolabilidad», Diario de Derecho, cit., 2020.

32 López Guerra, L., «Una monarquía parlamentaria», 1982, cit. supra. 
es, sin duda, el de la corona británica — como ya describiera García Pelayo—-, que ha conseguido pervivir con muy pequeñas interrupciones desde la ordenación estamental hasta la actualidad ${ }^{33}$. Esa permanencia ha hecho que la Corona se vea como una suerte de entidad ideal y un centro de imputación de actos ${ }^{34}$. El mantenimiento de formalidades, fórmulas y objetos regios históricos, contribuye también a reforzar ese halo simbólico que sostiene a esta entidad ideal. Por ello, es hasta cierto punto comprensible que algunas voces consideren que la inviolabilidad regia deriva de algún modo de esa idea de permanencia.

Pero más allá de las formalidades y simbolismos, los cambios acontecidos desde la ordenación estamental hasta la actualidad son evidentes. Las monarquías parlamentarias contemporáneas, explicaba Alzaga Villaamil en el proceso constituyente ${ }^{35}$, constituyen el último eslabón en la larga evolución de las formas monárquicas de gobierno hacia lo que se ha dado en llamar «Democracias coronadas». En éstas, la Monarquía, más que una forma de gobierno, ha pasado a ser una forma de Jefatura de Estado ${ }^{36}$, dado que el titular de la Corona no ostenta ya poder político alguno. En esa evolución, como es sabido, el principio monárquico ha ido cediendo a favor del democrático, pero parece haberse mantenido abierta la cuestión de si esa cesión ha llegado a su culmen en los sistemas actuales o si, por el contrario, el principio monárquico continúa manteniendo aún algún tipo de vigencia. En referencia a la monarquía británica, es muy conocida la expresión de Bagehot, que describe el sutil juego que combina componentes eficientes y componentes dignificados — simbólicos, nobles, solmenes- en el sistema de Westminster ${ }^{37}$ y en los sistemas políticos que, de algún modo, derivan de éste (especialmente los otros quince reinos de la Commonwealth ${ }^{38}$ ). La Corona de algún modo da soporte a la unidad y existencia política del pueblo ${ }^{39}$. Pero, ¿significa ello que sigue ostentando algún poder?

Se plantea también la cuestión, vinculada a ésta, de si esa simbólica permanencia y el mantenimiento de formalidades y expresiones de otros tiempos deben o no tener su impacto en la interpretación del estatuto regio y, especialmente, en relación con la prerrogativa de la inviolabilidad. Es decir, ¿subsiste un estatuto

33 García Pelayo, M., Derecho Constitucional Comparado, 5. a edición, Manuales de la Revista Occidente, Madrid, 1959, pp. 251-252.

34 Ob. cit., p. 294.

35 Alzaga Villaamil, O., «Intervención en la Comisión de Asuntos Constitucionales y Libertades Públicas», Diario de Sesiones del Congreso de los Diputados, 11 de mayo de 1978, pp2205-2217 (consultada la versión publicada en Alzaga Vilaamil, O. Discursos parlamentarios ( $y$ otras disertaciones), Marcial Pons Fundación CC, Madrid, 2019.

36 López Guerra, L., «Una monarquía parlamentaria», en J. De Esteban/ L. López Guerra, El régimen Constitucional Español, vol. II, Labor Universitaria, Barcelona, 1982, pp. 9 y ss.

37 Bagehot, The English Constitution, 1847; Boyce, The Queen's Other Realms, 2008, p.V; PETRIE, La Monarquía en el siglo Xx, Rialp, Madrid, 1956, pp. 58-64.

38 Escajedo San-Epifanio, L., «La Reforma de la Sucesión a la Corona en el Reino Unido de la Gran Bretaña y Norte de Irlanda, y en los «otros Reinos» de la Commonwealth of Nations», TRC 41, 2018, 213-239.

39 García Pelayo, Derecho Constitucional Comparado, cit., 1959, pp. 292-295. 
regio preconstitucional exceptuado de la Constitución o, por el contrario, sólo es simbólicamente relevante ese mantenimiento de formalidades antiguas? Nótese que la cuestión va mucho más allá de discutir si en la interpretación de constituciones deben o no ser tenidas en cuentas las causas y motivaciones que impulsaron su concreta elaboración histórica ${ }^{40}$. Se trata, si cabe, de algo más complejo que la trascendental discusión entre originalistas o los partidarios del activismo constitucional, entre partidarios de la autonomía de la norma y contextualistas, entre literalistas y finalistas» ${ }^{41}$. Al cuestionar si es posible mantener respecto al rey un estatuto preconstitucional, se cuestiona también si un sistema constitucional contemporáneo permite incoherencias internas. En la interpretación de las prerrogativas de los diputados y senadores contamos con un referente y es que TC español destacó la trascendencia que tenía interpretar la inmunidad y la inviolabilidad dentro del marco constitucional. No es adecuado, sentenció, cuestionar la ratio de esta prerrogativa, pero sin dejar, eso sí, resquicio alguno para que la inviolabilidad se convierta en impunidad ${ }^{42}$. Es cierto que, a diferencia de los parlamentarios, respecto del rey o reina sólo se ha previsto la inhabilitación (artículo 59.2 CE) y parece que la justiciabilidad quedaría limitada a la sede parlamentaria, pero la propia y existencia de dicha figura — la de la inhabilitación — es prueba de que dentro del sistema existen vías para evitar la impunidad.

\section{LA INVIOLABILIDAD REGIA, ¿ES UN FACTOR DE REFUERZO O, POR EL CONTRARIO, UN TALÓN DE AQUILES PARA LA CONTINUIDAD DE UNA MONARQUÍA?}

Expresiones como la de que la persona del Rey es sagrada e inviolable ${ }^{43}$ aparecían ya en algunos ordenamientos constitucionales de la Alemania del siglo XIX (como las Constituciones de Baviera y Baden, ambas de 1818, la de Würtemberg de 1819 o la de Hessen-Darmstadt de 1820) y la de Bélgica de 1813. Puede verse claramente cierta sintonía entre esas palabras y las expresiones constitucionales de algunas monarquías contemporáneas ${ }^{44}$. En muchos casos esto se ha producido, en

40 Lucas Verdú, P. «El Derecho constitucional como Derecho Administrativo. La 'ideología constitucional' del profesor García de Enterría», Revista de Derecho Político, 1982, n. ${ }^{\circ} 13$, pp. 7-52.

41 Molas I Batllori, I. (1998) En respuesta a la 2. ${ }^{a}$ pregunta de la Encuesta sobre la Orientación Actual del Derecho Constitucional, TRC1/ 1998, pp. 36-38.

42 Ya Silvela, F., «La inmunidad parlamentaria», en Revista General de Legislación y jurisprudencia, vol. 38 (76), 1980, pp. 32-52.

43 Esta fórmula se recoge literalmente en varios ordenamientos constitucionales alemanes del siglo XIX (como la Constitución de Baviera y la de Baden, ambas de 1818), la de Würtemberg, de 1819 y la de Hessen-Darmstadt de 1820), o en la Constitución de Bélgica de 1813, y mantiene cierta sintonía con algunas expresiones que emplean Constituciones contemporáneas, como la Constitución Española de 1978.

44 Véanse el artículo 88 de la Constitución de Bélgica, art. 13 de la Constitución de Dinamarca, art. 5 de la de Noruega, art. 42.2 de la Constitución de los Países Bajos y artículo 7 de la de Suecia. 
opinión de Jorge De Esteban, por inercia histórica ${ }^{45}$. Analizando esas expresiones y la forma en la que se interpretaban, junto con máximas como la the King can do no wrong, podemos llegar, de algún modo, comprender cómo han sido las luchas y tensiones que se produjeron en los procesos de transformación de las monarquías personales en monarquías constitucionales de diferente cuño. En cuanto a los antecedentes en España, las constituciones de 1837 y 1845 hacían referencia a la inviolabilidad con el añadido de que la persona del Rey era sagrada, un atributo que como detalla Fernández-Miranda Campoamor nace en la práctica en las organizaciones políticas de Oriente y de ahí se transmite a Occidente, donde perdurará hasta la progresiva implantación de los Estados democráticos ${ }^{46}$. La Constitución de 1869, calificada por las Cortes Constituyentes como «democrática», suprimirá este calificativo, refiriéndose a la persona del rey en los mismos términos que la Constitución de 1876, en su título IV, o el actual art. 56.3 CE, es decir, como persona inviolable y no sujeta a responsabilidad. La coincidencia terminológica, ¿hasta qué punto implica que son equiparables el estatuto regio de 1837 y el de 1978? Lo cierto es que en la doctrina no se ha planteado discusión en esos términos, pero la tendencia a la interpretación literal ha llevado a que algunas voces prácticamente equiparen las citadas afirmaciones constitucionales, obviando las importantes diferencias entre los sistemas políticos de 1837, 1876 y 1978. Siguiendo el consejo de autores como Bryce o García Pelayo, entre muchos otros, parece sin embargo conveniente prestar la debida atención a la historia. Abordar la materia constitucional requiere ser tanto bistoriador como jurista ${ }^{47}$. En términos formales y estáticos determinadas monarquías históricas y las actuales pueden dar una sensación de homogeneidad armónica ${ }^{48}$, pero su ubicación en sistemas políticos tan diferentes es una clave ineludible en la interpretación de su realidad institucional.

\section{Significados que se atribuyen a la máxima the King can do no wrong}

Se considera que el uso más antiguo de la máxima the King can do no wrong es el que entiende que el Rey no puede, por definición, obrar mal porque sus derechos tienen un origen divino. Esta interpretación se asocia con el desarrollo que algunos glosadores hicieron del Digesto Justinianeo, en especial del principio princeps legibus solutus est. Adviértase, no obstante, que otras expresiones recogidas por Ulpiano llevan a pensar que esa interpretación del Digesto no era del todo

45 De Esteban, J., «La confusa inviolabilidad del Rey», en Diario de Derecho de 28 de julio de 2020.

46 Fernández-Miranda Campoamor, C., «La irresponsabilidad del Rey: El refrendo: evolución histórica y regulación actual», Revista de Derecho Político, 1998, cit., p. 229.

47 García Pelayo, M., Derecho Constitucional Comparado. Ed Libro Universitario, 1991, p. 59.

48 Vid. Ferrando Badía, J. «Presentación», en Ferrando Badía. (coord.), Regímenes Políticos Actuales, Segunda edición corregida y aumentada, Tecnos, 1985, pp. 41-43, con referencias a Lucas Verdú, P. Principios de Ciencia Política, vol. I, Tecnos, Madrid, 1971, p. 29. 
pacífica. Así, por ejemplo, cuando se indica que si la voluntad del emperador tiene fuerza de ley es porque el pueblo, al investirlo, le ha transferido su propio poder y autoridad ${ }^{49}$, o al apuntar que — aunque no se le pueda obligar mediante las autoridades terrenales- no por ello deja el príncipe de estar vinculado en su conciencia, dado el origen divino de toda ley. Algunos intérpretes contemporáneos, de hecho, han criticado que algunos glosadores pervirtieran una doctrina en la que se atisbaban elementos clásicos del derecho constitucional, al entender que la exención del emperador de la observancia de ciertas normas podía interpretarse como tendente a un absolutismo irresponsable $e^{50}$.

En una segunda interpretación de la máxima, algo cercana a esta primera, se considera, en cambio, que en el caso de que las acciones de un Rey no sean legales, no existe remedio alguno para repararlas en las vías ordinarias. Es la que se ha dado en llamar interpretación procedimental (o remediadora) de esta máxima. Pero será una tercera interpretación de esta máxima la que adquiera, al menos en Inglaterra, su vigencia más reconocida, en un sentido en que no tardará en vincularse en la práctica con la institución del refrendo. Veámoslo con cierta perspectiva histórica. La literatura anglosajona comienza a narrar la evolución de las prerrogativas regias hasta su actual interpretación tomando como referencia el reinado de Guillermo I el Conquistador (1066-1087), que fue el primer Rey de Inglaterra de origen normando $^{51}$. La inmunidad soberana comprendía el respeto y la inviolabilidad que era imprescindible para el soberano y sus embajadores que viajaban a otros países, y fue el Common Law el que se considera que en aquel tiempo extendió la aplicación de este tratamiento al soberano dentro de su propio país ${ }^{52}$. No existía un poder superior al del Rey, su posición estaba por encima de la Ley, y sólo podía ser juzgado si el propio monarca aceptaba la sumisión a los tribunales. Un siglo después de ese reinado, la línea normando-angevina tomaría el poder y el rey Enrique II adoptaría el título de Rey de Inglaterra, consiguiendo para este trono una cierta estabilidad $^{53}$. En la realidad, sin embargo, tanto él como sus herederos continuaron siendo fundamentalmente duques franceses y conservaron las tradiciones y la lengua, además de importantes dominios en Francia. Su interés en Inglaterra, apuntan los historiadores, fue fundamentalmente económico.

La situación, con todo, comenzará a cambiar de forma notable a partir de Juan I. A pesar de ser el más joven de los cinco hijos de Enrique II y Leonor de

49 Vinculado a la máxima Quad Omnes Tangit ab Omnibus Approbetur (lo que concierte a todos, ha de ser aprobado por todos), tal y como se recogería en el primer parlamento inglés, en 1295, durante el reinado de Eduado I.

50 Especialmente crítico es Esmein, A. «La Maxime Princeps legibus solutus est dans l'ancien droit public francais», en P. Vinogradoff (ed.), Essays in Legal History, Oxford, 1913, pp. 201 a 214; HonOrÉ,

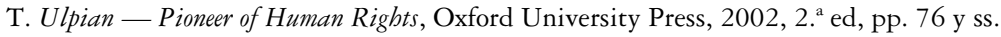

51 Seidman, G. I. «The Origins of Accountability», cit., 2005, vol 49 (2), pp. 393-480.

52 De Seife, R. J. A., «The King is dead, long live the King! The Court-created american concept of immunity: the negation of equality and accountability under law», Hofstra Law Review, vol. 24, n. ${ }^{\circ} 4,1996$, pp. 981 y ss.

53 Lyon, B., A Constitutional and Legal History of Medieval England, 2. ${ }^{\circ}$ ed, 1980, pp. 228-230. 
Aquitania, Juan I (Juan sin Tierra), terminaría sucediendo a su hermano Ricardo Corazón de León en circunstancias un tanto adversas. Aconsejado por el papado trató de hacer frente a su compleja situación aceptando la Carta Magna (1215), pero ésta no impidió un alzamiento en contra de su persona. Es en ese escenario cuando el repentino fallecimiento de Juan I provoca que Enrique III acceda al trono con tan solo 9 años y en una situación muy debilitada (1216). Con una Inglaterra parcialmente ocupada por los rebeldes, Enrique III, indefenso ante las demandas papales y de los barones, no tendrá poder ni capacidad para actuar mal y ello sustentará el desplazamiento de la responsabilidad regia hacia los ministros reales, que eran en suma los responsables de las decisiones.

Desde ese humilde comienzo, el de la minoría de edad de Enrique III tras la aprobación de la Carta Magna, dirá Lowell que la máxima se desarrollaría, de forma gradual, hasta convertirse en un principio cardinal de la Constitución inglesa ${ }^{54}$. Muy poco tiempo después, y de forma progresiva, se convertirá en el punto de partida de las normas estatutarias y del desarrollo de mecanismos de rendición de cuentas $^{55}$. Durante el reinado de Eduardo I, hijo de Enrique III, esos mecanismos de desplazamiento de la responsabilidad se acentuarán ${ }^{56}$. Ello no sólo tendrá impacto en la exigibilidad de responsabilidad al monarca ${ }^{57}$, sino que, viendo que resultaba menos difícil exigir responsabilidad y controlar parlamentariamente a sus ministros, será también la base para una progresiva reducción de las acciones que los monarcas podrán realizar por si mismos, sin necesidad de refrendo. Vemos que aquí se hace ya visible algo que se reforzaría en los siglos xv y XVI, cuando los juristas ingleses desarrollaron el concepto de los «dos cuerpos del Rey» o de las duales capacidades legales de la Corona. La transformación del sistema será aún más evidente en los siglos XVII y XVIII, cuando la percepción medieval y personalista del trono se considerará plenamente sustituida por ese concepto dual, que combina atributos personales y atributos institucionales. No obstante, y como se verá especialmente en los juicios de Carlos Estuardo o de Louis XVI (vid. infra), algunos sectores seguirán defendiendo la idea de que el estatuto regio es derivación los derechos divinos del monarca o, cuando menos, una contraprestación a éste.

Cabe hallar, no obstante, algunas interpretaciones más sobre esta máxima. Bracton, por ejemplo, dirá que el Rey no puede obrar mal porque es la Ley la que hace al Rey ${ }^{58}$ y hay quien aprecia en ello una cuarta lectura de esta máxima: la Ley, limita el poder del Rey. A diferencia de lo que veremos en Francia, durante el juicio a Louis XVI, o en los debates actuales de las democracias coronadas, en Inglaterra no

54 Lowell, A. L., The Government of England, Macmillan, 1908.

55 Seidman, G, cit., 2005, p. 405.

56 KIRK, R., The Roots of American Order, 1974, p. 403 (consultada la edición de 2003, publicada por Intercollegiate Studies Institute, ISI Books).

57 Wade, W., «That is the Crown? », en Maurice Sunkin/ Sebastian Payne (eds.), The Nature of the Crown: A legal and Political Analysis, Oxford University Press, 1999, p. 26.

58 «The King is under God and the law; for the law maketh the King». 
existía la referencia de un texto constitucional y para algunos autores, como el propio Bracton, la referencia de esa Ley será la Carta Magna de 1215. De acuerdo con ella, dirá Bracton, el Rey no tiene ya poder para hacer el mal o la injusticia, porque todo acto contrario a la ley sería nulo. En esa línea cabe considerar las reflexiones del obispo Burnet (1689) o de Sir Roger L'Estrange (en su Plea for a Limited Monarchy de 1660$)^{59}$. Muy cercana a esta acepción encontramos una última, según la cual se considera que el Rey es perfectamente capaz de obrar mal, pero no está legitimado para hacerlo. Desde una perspectiva racional, este tipo de afirmaciones podrían llevar a debatir sobre qué es lo que ha de hacerse cuando el rey realiza «actos contrarios a la Ley». ¿Cómo han de anularse los actos que un monarca realiza contra la Ley — siguiendo la propuesta de Bracton—, o cómo ha de responderse si, en la línea de lo que apunta Burnet, un rey actúa sin legitimación? Cabría pensar en la necesidad de mecanismos que reconduzcan la mala conducta de un monarca, que restauren la legalidad, o decantarse, por el contrario, por esperar un cierto compromiso de ejemplaridad de quien asume la Jefatura del Estado — en la línea de lo que el profesor Solozábal Echavarría afirmaba sobre la CE de $1978^{60}$. En un punto intermedio estaría la tesis de Blackstone, quien dirá en sus comentarios que el Rey no sólo es incapaz de obrar mal, sino que lo es incluso de pensar mal; nunca puede tener la intención de hacer algo impropio porque en él no hay locura ni debilidad ${ }^{61}$. En vez de cómo incapacidad para obrar mal, cabría ver esa máxima de que no puede realizar entuerto como una suerte de compromiso ético — en la línea de la ejemplaridad a la que apuntaba Solozábal_-, siendo así que, con su coronación, se espera del monarca que vel por el mejor interés de sus súbditos. Desde esta perspectiva sería posible también contemplar la idea de John Fortescue según la cual, con la coronación, no es que se haya dado un reino al Rey, sino que es el Rey el que ha sido dado a un pueblo ${ }^{62}$.

\section{La inviolabilidad, ¿refuerza a la persona del monarca o a la institución de la Corona?}

Los límites del poder y de la rendición de cuentas ante los ciudadanos son considerados una cuestión esencial en los sistemas democráticos ${ }^{63}$, aunque desde la perspectiva del Derecho constitucional la doctrina describe la rendición de

59 Véase sobre estas y otras citas históricas, Greenberg, J., «Our Grand Maxim of State, 'The King can do no Wrong», en History of Political Thought, vol. 2, 1991, pp. 216 y ss.

60 Solozábal Echavarría, J. J., La sanción y promulgación de la ley en la Monarquía Parlamentaria, Tecnos, Madrid, 1987.

61 Blackstone, W. "Chapter Seventh: Of the King's Prerogative», en Commentaries on the Laws of England, Claredon Press, 1765-1769 Oxford, 230 y siguientes, en especial 239. Consultado en The Avalon proyect — Documents in Law, History and Diplomacy, accessible en: https://avalon.law.yale.edu/18th_century/ blackstone_bk1ch7.asp

62 SkeEl, C. A. J., «The influence of the Writings of Sir John Fortescue», Transactions of the Royal Historical Society, vol. 10, 1916, pp. 77 a 114. Texto disponible en Cambdridge Core.

63 Schmitter, P./ Terri, L. K., «What Democracy is... and is not», Journal of Democracy, 1991, pp. 4 yss. 
cuentas como un concepto paraguas, en el que se ha dado cobijo acepciones de muy variable contenido ${ }^{64}$. Por más que la idea de que los cargos públicos rindan cuentas más que puedan resultar evocadora, los términos en los que ello se ha venido produciendo a veces resultan ambiguos o incluso algo decepcionantes para la ciudadanía. En Inglaterra la rendición de cuentas, fuertemente vinculada en un inicio con cuestiones de administración contable, puede trazarse hasta, como mínimo, la Carta Magna (1215) —o incluso antes ${ }^{65}$ — , aunque el uso más extendido de la rendición de cuentas (accountability) se vincula en la actualidad con las promesas de una gobernanza justa y equitativa, obligando al actor a explicar o justificar ante los ciudadanos sus conductas y decisiones ${ }^{66}$. Planteamientos originarios relacionados con la efectividad y la eficiencia de la gobernanza pública han dejado, además, paso a una rendición de cuentas que gradualmente se va convirtiendo en un objetivo en sí misma, toda vez que se vincula con el buen gobierno y la buena administración ${ }^{67}$ y evoca imágenes como las de confiabilidad, lealtad o justicia ${ }^{68}$. No obstante, toda esta evolución coincide con dos elementos más: los tránsitos del poder y la responsabilidad desde el monarca hacia el gobierno, y las concepciones duales de la Corona, tendentes a separar la institución del cuerpo o persona que en cada momento ostenta el cargo. En el Reino Unido se consideró históricamente que la Corona no podía ser objeto de persecución penal o proceso civil, con muy pocas excepciones, aunque la Crown Proceedings Act de 1947 modificó sustancialmente esta postura respecto de algunos procesos civiles. No obstante, esa norma no afecta a la persona del monarca, que sigue siendo considerada personalmente inmune a acciones criminales o civiles. En Canadá, donde reina también — como ya se ha dicho_- Isabel de Windsor, se ha regulado estatutariamente que la Corona es responsable ante los tribunales, como lo sería cualquier persona, a diferencia de lo que se considera en el Common Law.

En los Países Bajos la Constitución recoge desde 1848 que el monarca es inviolable, y ello es entendido en el sentido de que el monarca debe permanecer políticamente neutral y que serán los miembros del gobierno los que responderán ante el Parlamento por las políticas gubernamentales. Por su parte, el artículo 88 de la Constitución belga de 1830 se pronuncia en términos similares, aunque la construcción gramatical del enunciado puede prestarse a matices de interpretación: «La persona del rey es inviolable; sus ministros son responsables». En la documentación de la Cámara de representantes belgas se interpreta que a nivel político el Rey no es responsable ante el Parlamento (lo son los ministros federales). Y, por

64 Harlow, C., «Accountability and Constitutional Law», en M. Bovens/ R. E. Goodlin/ T. SCHILlemans, The Oxfiord Handbook Of Public Accountability, Oxford Handbooks Online, 2014.

65 Dubnick, M. J., Seeking Salvation for Accountability, presentado en Annual Meeting of the American Political Science Association, 2002, pp. 7-9.

66 Bovens, M., «Analysing and Assessing Accountability: A Conceptual Framewrok», European Law Journal, 2007, 13 (4), pp. 450.

67 Mulgan, R., Holding Power to Account: Accountability in Modern Democracies.

68 Palgrave, 2003. 67 Bovens, M. cit., European Law Journal, 2007. 
cuanto se refiere a responder ante los tribunales: a nivel penal el rey no puede ser perseguido, arrestado ni condenado por la comisión de un delito, y a nivel civil el rey de Bélgica no puede ser llevado ante los tribunales ni siquiera por cuestión de contratos privados relativos a su patrimonio. Esta inviolabilidad regia se considera que fuerza a la monarquía a tener un papel reservado, si bien al mismo tiempo garantiza su permanencia y le permite desempeñar un rol conciliador, por encima de los grupos políticos, sociales y filosóficos. Por su parte, la Constitución danesa (art. 13) establece que el Rey no responde por sus acciones y que su persona es sacrosanta, siendo los ministros los que responden por la conducta del gobierno. También es sagrada la persona del rey en Noruega, donde no puede ser censurado ni acusado, si bien se considera que esa inmunidad no se extiende a su capacidad personal para ser propietario o actor respecto de bienes inmuebles, o cuando actúa fuera de las funciones que le corresponden como monarca ${ }^{69}$. En Luxemburgo, por último, la Constitución establece que el Gran Duque es inviolable y que ello impide que sea juzgado ante ninguna jurisdicción, si bien en 1998 se suprimió la referencia a la sacralidad que había sido recogida en la Constitución de $1856^{70}$.

Con matices que diferencian a unas de otras, las Constituciones españolas de $1837,1845,1869$ y 1876 reconocen la inviolabilidad de un monarca que, aún en este último caso, tiene una fuerte incidencia sobre el poder ejecutivo. Por su parte, inviiolable será reconocido también el Jefe de Estado que en el sistema franquista que «personifica la soberanía nacional» y «dirige la gobernación del Reino» (art. 6 de la derogada L.O 1/1967). Existen, sin duda, cercanías en las formas de unas y otras expresiones y, en algunos casos, coincidencias en las premisas que sirven de base a esa inviolabilidad, pero difícilmente cabe sostener que en estos casos la interpretación literal deba excluir de plano la importancia del contexto o sistema en el cuál se ubican tales normas. Es importante también tener en cuenta la realidad social de los tiempos o el espíritu y finalidad con el que la inviolabilidad fue recogido en la norma en cada caso. Si algo tienen en común todas estas figuras, como es también el caso de las prerrogativas reconocidas a los parlamentarios, es su contribución a reforzar no sólo a monarcas concretos (como el jovencísimo Enrique III), sino al papel que la Corona cumple respecto del Estado en cada uno de esos casos. En perspectiva histórica, la inviolabilidad resulta un principio conservador, en tanto la estabilidad y continuidad de un monarca concreto representó, en muchos contextos, el mantenimiento de una forma política concreta. Podemos ver un reflejo de ello en la defensa que el Conde de Séze hace de Louis XVI: «los Reyes debian ser inviolables, pues de lo contrario se vería a cada paso perturbada la tranquilidad y la felicidad de la república», a lo que añade que «es más útil para la quietud del pueblo mismo no hacer responsables a las personas de los Reyes». Y es que la elección de un

69 Andenæs, M. T./ WilberG, I., Grunnloven-Kommentarutgave, vol. I., Universitetsforlaget, Oslo, 1983 , p. 98.

70 Fettereissen, M. / Pochon, B. L. L'État du Grand-duché de Luxembourg, Larcier, 2014, p. 23. 
monarca concreto - y con ello la adhesión también de la Jefatura de Estado a su línea sucesoria - ha sido vista en esos contextos como una opción más adecuada que sus alternativas, y la prerrogativa de la inviolabilidad aparece así intrínsecamente vinculada con un objetivo institucional: el refuerzo de esa opción - la Jefatura de Estado monárquica — frente a diferentes alternativas republicanas. Desde esa perspectiva cabe prestar atención, por ejemplo, al Informe de la Comisión Soenens en Bélgica, que afirmaba que el Constituyente, al instaurar la Monarquía, desea entre otras cosas que la Jefatura de Estado deje de cuestionarse periódicamente, siendo esa la razón por la que asocia la Jefatura de Estado al prestigio impersonal y duradero de una dinastía ${ }^{71}$. La heredabilidad del cargo, explicará Jean Baptiste Nothomb en el proceso constituyente de Bélgica (1831), es una ficción política, como también lo es la inviolabilidad regia; son dos ficciones, dos excepciones al orden social que, en tanto han sido establecidas por la soberanía popular, igualmente pudieran romperse de inmediato en un caso extremo ${ }^{72}$.

El caso es, y de ahí la pregunta de este apartado, que la peculiar naturaleza del vínculo de un Estado con una dinastía concreta hace de la inviolabilidad regia un elemento ambivalente, porque su rigidez parece abocar, llegado el caso, a elegir entre excusar los actos de un monarca concreto, o derrocarlo y abrir paso a una forma política republicana. Históricamente, como advierte Clayton Roberts, la inviolabilidad regia claramente ata de manos al Rey ${ }^{73}$, porque una vez que sus funciones se transforman en simbólicas el Rey pasa a tener respecto del Estado otro tipo de utilidad. Bagehot describirá que si bien no es una parte eficiente de la constitución, la Corona es una de las «dignified parts» de ésta y contribuye a infundir en el pueblo respeto por la Constitución. En el mismo sentido, Fernández Segado describirá una suerte de relaciones anímicas entre la institución monárquica y la ciudadanía, que hacen que se reconozca a aquélla una incalculable utilidad y otros autores, como Torres del Moral, destacarán que el monarca encarna la unidad del poder estatal, la unión entre sus órganos ${ }^{74}$. Como dirá Wynants, algunos monarcas son polos de identificación de la colectividad ${ }^{75}$. Bagehot dirá de la Reina británica, que ésta hace inteligibles el gobierno ${ }^{76}$ y los vínculos con la Comonwealt C $^{77}$, y suministra enfoques para ciertos tipos de patriotismo ${ }^{78}$. Y, por su parte, en países

71 Rapport de la Commission Soenens, Belgisch Staatsblad - Moniteur belge, 6 de agosto de 1949, p. 7591.

72 Tomado de Huyttens, E., Discussions du Congrès National de Belgique, 1830-1831, 5 vol. 1, Wahlen, Bruselas, 1844-1845.

73 En Growth of Responsible Government, Cambridge, 1966, p. 4; en el mismo sentido, MaLCOLM, J. L., «Doing No Wrong», cit., 1999, p. 162.

74 Torres del Moral, A. «La monarquía parlamentaria española», Tecnos, Madrid, 1991; Torres Del Moral (dir.), Monarquía y Constitución, Madrid, Colex, 2001.

75 Wynants, P., «Trois paradoxes de la monarchie en Belgique», en La revue nouvelle. La Monarchie dans l'ètat Belge, 2002, número 03/04, pp. 12-16.

76 Bagehot, W. La Constitución inglesa, cit., p. 58.

77 García Pelayo, M., Derecho Constitucional Comparado, cit., 1991, p. 300.

78 Jennings (1968), The British Constitution, Cambridge, 5. .a ed, p. 120. 
tan política y culturalmente plurales como el de Bélgica, con sistemas que avocan a gobiernos de coalición, el monarca es una figura que ayudan a visualizar, desde la historia colectiva, la unidad de la sociedad.

La fragilidad de esta construcción se evidencia, eso sí, cuando se plantea la necesidad de proteger a la Corona y a sus funciones, respecto de la persona concreta de un monarca o de algún miembro de su dinastía. En el verano de 2020, como ya se ha dicho, el rey emérito Juan Carlos I de España decía trasladar su residencia al extranjero para contribuir, citando textualmente sus palabras, a la «tranquilidad y sosiego» que la Jefatura de Estado necesita. Visto desde el lado opuesto, parece que ante una situación como la planteada entre el emérito y su sucesor el sistema constitucional carece propiamente de instrumentos con los que contribuir a tal sosiego. A través del refrendo se ha ido creando históricamente una ficción de irresponsabilidad del monarca respecto de sus actos institucionales ${ }^{79}$, y como complemento a éste se ha configurado un modelo de Jefatura de Estado en el que su titular tiene funciones simbólicas o de escasa fuerza, al tiempo que se le exige explícita o implícitamente en la Constitución — según el país de que se trate-, que mantenga una posición de neutralidad política. Las Constituciones, sin embargo, no suelen recoger ninguna referencia explícita al hecho de que - en coherencia con el sistema constitucional- ya fuere como ciudadano ya como persona que ostenta un cargo constitucional, los actos del Monarca, sin excepción, deben de algún modo quedar sometidos a la Constitución y al resto del ordenamiento jurídico (9.1 CE). Desde las peligrosas simplificaciones que la distancia histórica permite se hace extraña la insistencia en señalar, por ejemplo, una suerte de deuda histórica que los españoles contrajeron respecto un Monarca que, según algunos discursos vienen reafirmando, renunció a continuar un régimen autocrático, como si la renuncia a tal alternativa — si es que era realmente posible — es algo que los súbditos de algún modo debieran premiar $^{80}$ o a lo que se debería rendir tributo $^{81}$. Conviene no perder de vista, en cualquier caso, que al tratar de evitar que un monarca responda en democracia, se reconoce una inherente debilidad a ésta. La inexistencia de mecanismos con los que depurar, en su caso, la responsabilidad, priva al monarca de poderse defender de acusaciones infundadas y lo expone peligrosamente al impacto que puedan tener las actuaciones concretas de miembros de su propia dinastía. Llegada una crisis, la inexistencia de mecanismos adecuados, pareciera que inexorablemente nos lleva a tener que escoger entre mantener una monarquía (tal y como está) o reformar el sistema hacia una república.

79 Fernández-Miranda Campoamor, C. «La irresponsabilidad del rey: evolución histórica y regulación actual», Revista de Derecho Político, 1998, n. ${ }^{\circ} 44$, p. 232.

80 Amorós, M. (2014). 75 años después. Las claves de la Guerra Civil Española. Conversación con Ángel Viñas, Ediciones B.

81 Íbidem. 


\section{RECONOCIDA LA INVIOLABILIDAD, ¿ES POSIBLE JUZGAR AL MONARCA? DOS JUICIOS HISTÓRICOS Y ALGUNAS NOTAS CONTEMPORÁNEAS}

Históricamente, los más encendidos debates sobre el acomodo constitucional de un monarca no han sido tanto doctrinales, como propiciados por la necesidad de dar respuesta a actos concretos de monarcas concretos. Así puede comprobarse, como se verá a continuación con más detalle, en las actas parlamentarias de las discusiones que precedieron al juicio y posterior ejecución de Carlos Estuardo, en Inglaterra, y de Louis XVI, en Francia. En otro tipo de escenarios constituyentes, sin embargo, han sido cuestiones como las de las funciones regias o el refrendo las que han concentrado la atención, toda vez que - aceptada la forma de gobierno monárquica - la posibilidad de que el Rey o la Reina contravengan de algún modo el ordenamiento jurídico apenas es contemplada.

\section{Juicio histórico a un monarca que no podía realizar entuerto: Carlos Estuardo (Carlos I de Inglaterra)}

El juicio a Carlos de Estuardo, en 1649, como sucederá más de un siglo después en el de Luis XVI, concluyó con un regicidio que dio paso temporal a una República ${ }^{82}$. «Ninguna corte terrenal tiene jurisdicción sobre mí, que soy vuestro Rey» proclamaría Carlos I de Inglaterra y Escocia durante el proceso por el cuál la Cámara de los Comunes creaba en 1649 una corte para juzgarlo de alta traición y de «otros altos crímenes» ${ }^{83}$. Hijo de Jacobo I, este monarca pasaría a la Historia por, entre otras cosas, las destacadas tensiones que durante su reinado mantuvo con el Parlamento y que, finalmente, lo llevarían a ser juzgado y ejecutado. Según su opinión, aquellos que pretendían juzgarlo habían nacido como súbditos suyos, mientras que él, en su Coronación, había sido ungido por Dios ${ }^{84}$.

La corte, sin embargo, consideró que ningún hombre estaba por encima de la Ley. Como recogería tiempo después Sir Edward Coke en sus Reports (1826), una máxima igualmente venerada del Derecho inglés explica que, si bien el Rey no está sometido a ningún hombre, no es menos cierto que lo está a Dios y a la Ley, porque es la Ley la que hace al Rey ${ }^{85}$. En consecuencia y sin el consentimiento del Monarca ni la participación de la Cámara de los Lores, la Cámara de los Comunes

82 En Inglaterra, se produciría una restauración monárquica tras el mandato de Orwell, y en Francia en 1814 .

83 Malcolm, J.L., «Doing No Wrong: Law, Liberty, and the Constraint of King», Journal of British Studies 38, abril de 1999, pp. 161-186.

84 Cita de David Hume, The History of England: From the Invasion of Julius Caesar to the Abdication of James

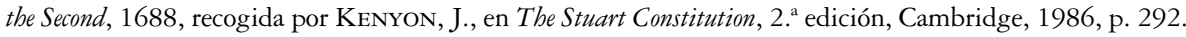

85 «The King is under God and the law; for the law maketh the King». 
creó un tribunal ad hoc para juzgar al Rey. Apenas un mes después de iniciarse el juicio, Carlos Estuardo fue decapitado (30 de enero de 1649) y se estableció una República, la llamada Commonwealth of England ${ }^{86}$.

\section{El juicio contra Louis XVI, inviolable según la Constitución francesa de 1791}

Si el proceso contra Carlos Estuardo fue precipitado (o no) y si lo fue también la decisión final, ambas son cuestiones que durante largo tiempo se discutirían en la doctrina inglesa y cuyos ecos llegarían, entre otros, al proceso contra Louis XVI. En torno al estallido de la Revolución de 1789 se produjeron en Francia dos importantes debates sobre la inviolabilidad regia de dicho monarca. El primero de ellos, tuvo lugar en la Asamblea Constituyente de la que surgiría la Constitución de 1791. El segundo de ellos, poco después, cuando en otoño de 1792 Luis XVI fue acusado de traición ante la Asamblea Nacional francesa. En lo referente a Louis $\mathrm{XVI}$, el debate en la asamblea constituyente estuvo muy influenciado por el hecho de que, tras varios intentos fracasados, en junio de 1791 el rey había huido de Las Tullerías, dejando constancia escrita de su malestar por el trato recibido y revocando su consentimiento a las medidas que habían sido instauradas tras la Revolución ${ }^{87}$. La Familia Real fue, sin embargo, interceptada poco después en Varennes y devuelta en París. Excusando su huida — que algunas voces llegaron a juzgar de involuntaria - en la Asamblea Constituyente se abrió paso la propuesta de restituirlo en el cargo y reconocer su inviolabilidad, a cambio de que prestase consentimiento a la nueva constitución. No todas las voces, sin embargo, eran favorables a tal restitución. Con muy duras palabras, a las que ya hemos hecho alusión con anterioridad, se dirigía Maximilien Robespierre a quienes defendían al Monarca en la Asamblea Constituyente: «Es a vosotros a quienes pregunto, vosotros que sostenéis ese sistema tan enérgicamente: si un rey degollase a vuestro bijo en vuestra presencia, si ultrajase a vuestra mujer o a vuestra hija, ¿le diríais acaso: Sire, estáis en vuestro derecho, ¿os hemos permitido todo? (..) ;El rey es inviolable! También lo sois vosotros. Pero, ¿tenéis por ello la facultad de cometer un crimen? (...) ; El rey es inviolable! Pero, ¿acaso no lo son también los pueblos? El rey es inviolable por una ficción; los pueblos por el derecho sagrado de la naturaleza. ¿Y qué bacéis, cubriendo al rey con la égida de la inviolabilidad, sino inmolar la inviolabilidad popular a la real?».

Finalmente, la Constitución de 1791 restituyó a Louis XVI y lo declaró inviolable, pero apenas un año después se iniciaría en las Cortes un proceso contra él -a quien las actas vaticanas se referirían después como el Rey Mártir- y contra su esposa, María Antonieta. Terminado el proceso, y condenados ambos,

86 An Act Declaring and Constituting the People of England to be a Commonwealth and Free-State, de 19 de mayo de 1649. Consultada la versión publicada en 2008.

87 Doung, K., «The People as a Natural Disaster: Redemptive Violence in Jacobin Political Thought», American Political Science Review, 2017, 111/4, pp. 786-800, 787. 
fueron ejecutados en la guillotina. Como un elemento clave, diferenciador respecto al juicio de Carlos Estuardo, no debemos pasar por alto que en el caso de Louis XVI la Revolución francesa había transformado en muy poco tiempo el Antiguo Regimen y abrió paso a nuevas realidades. En ese escenario la existencia de un Rey resultaba un elemento de tensión y, hasta cierto punto, de confusión ${ }^{88}$. Se dudaba de la viabilidad de una monarquía constitucional ${ }^{89}$, más aún en un escenario en el que la Familia Real había tratado de huir y buscar apoyos en el extranjero. Algunos líderes políticos trataron de explicar la huida del monarca bajo la ficción de un secuestro ${ }^{90}$, pero otros — como hemos visto- se preguntaban por qué debía reconocerse al Rey Louis XVI una inviolabilidad que, sin juicio sobre sus acciones recientes, implicaba reconocer su inocencia. La constitución monárquica y el reconocimiento de una prerrogativa de inviolabilidad fueron dos mecanismos que no consiguieron consolidarse, porque por más que recogidos en el tenor literal de la Constitución no estaban protegidos por un amplio consenso. Apenas un año después, los republicanos denunciaron a Louis XVI ante la Convención Nacional e impulsaron su enjuiciamiento ( «Los legisladores ban anticipado la decisión considerándolo inocente e inviolable, pero esa no es la voluntad del pueblo») ${ }^{91}$.

Los miembros de la Convención Nacional eran conocedores de las críticas que en Inglaterra había recibido el juicio a Carlos Estuardo, no tanto por haber terminado con su condena, sino por la precipitación y el poco cuidado que se habían tenido en las formas. «Debemos ser más solemnes en este juicio», dirá Mailhe en la preparación del juicio a Louis XVI, y otras voces, como la de Jean-Paul Marat, recordarán que no se trataba de un juicio ordinario ${ }^{92}$. Se abordó en primer lugar si un monarca, reconocido como inviolable en la Constitución, podía ser o no procesado y en su caso cómo. Según Mailhe, la inviolabilidad impedía que el Rey fuera juzgado por los poderes constituidos, pero no por la Nación, dado que esto último hubiera implicado que en virtud de la Constitución el Rey había pasado a ser superior $\mathrm{o}$, al menos, independiente de la Nación. Otras voces, sin embargo, defendieron que la inviolabilidad no impedía el juicio, sino únicamente la posibilidad del castigo. Así, el Marqués de Condorcet, aún aceptando que Louis XVI era inviolable, consideraba que dicha inviolabilidad no impedía enjuiciar al monarca. La inviolabilidad, en su opinión, libraba al monarca de un posible castigo, pero no de un posible juicio. Un rey, entendía, podría ser legalmente condenado por sus acciones, aunque no pudiera ser castigado sin vulnerar el principio de irretroactividad. En relación, esta segunda cuestión, la de la retroactividad,

88 Carney, G. «The State Trials of Louis XVI and Marie-Antoinette», Owen Dixon Society eJournal, 2017, pp. 3-4; DuOng, K. «The People as a Natural Disaster», American Political Science Review, 2017, cit., p. 787.

89 Tacketт, T., When the King Took Flight, Harvard University Press, Cambridge, 2003, pp. 179-202.

90 Doung, K., «The People as a Natural Disaster», cit., 2017, pp. 787-788.

91 BaCKer, K. M., The Old Regime and the French Revolution: Essays on French Political Culture in the 18th Century France, 1987, pp. 275-277.

92 Así, en Mavidal, J. / Laurent, E., Archives parlementaires (1787á 1860), Institut d'Histoire de la Révolution Française, P. Dupont, Paris, 1862-1913, 47, pp. 69-70. 
existían además posiciones que ya se había expresado en la Asamblea Constituyente (julio de 1791). ¿Queremos terminar la Revolución, o queremos volverla a empezar?, retaba Barnave en su réplica a Robespierre ${ }^{93}$. La constitución escrita reconocía al Rey su inviolabilidad y sólo la Constitución, dirá Barnave, podría prever en qué casos cabe descalificar al Rey. Si no fuera así, un rey esencialmente independiente se volvería dependiente de aquel que lo juzgue.

Las leyes políticas, recuerda, tienen entre sus objetivos evitar la arbitrariedad y en las situaciones de inestabilidad no deberían cuestionarse esas reglas. Esa misma base argumental, esto es, la de la relevancia de mantener los compromisos constitucionales, será la que destaque Charles-François-Gabriel Morrison en su discurso ¿Puede Luis XVI ser juzgado?94. Aunque una Nación soberana no tiene más ley que su propia voluntad y mantiene el derecho a cambiar las leyes, los cambios no deberían tener efectos retroactivos porque ello daña los principios más básicos de la justicia. MORRIsOn concluía que el pueblo podía decidir abolir la Monarquía, pero no deberían juzgar los crimenes realizados por Luis mientras era inviolable ${ }^{95}$. Terminados los debates, la Asamblea, por mayoría, resolvió revocar la inmunidad del Rey y así comenzó en su contra un proceso ${ }^{96}$ que terminaría, como es sabido, con él y su esposa en la guillotina.

\section{Los debates contemporáneos sobre la inviolabilidad regia}

A diferencia de los casos de Carlos Estuardo o de Louis XVI, los debates contemporáneos sobre la inviolabilidad regia y su ámbito de aplicación tienen que ver, sobre todo, con actos que monarcas concretos o miembros de sus familias realizan en sus vidas privadas. Las monarquías parlamentarias contemporáneas, como se ha dicho, otorgan al monarca una función eminentemente simbólica y desde esa posición resulta difícil de imaginar que ningún Jefe de Estado en su sano juicio se plantee retar a los poderes públicos. Terceros ajenos a una familia real que reivindican un parentesco biológico no reconocido o cuestiones relacionadas con gestiones dudosas de su patrimonio personal son aquellas que con más insistencia se presentan cuando se discute sobre la inviolabilidad y ello ha hecho también necesario abordar si ésta alcanza o no (y hasta qué punto) a los actos privados. Algunos sectores doctrinales defenderán así la inviolabilidad como una inmunidad frente a la persecución penal, mientras que otros — en un sentido más amplio— consideran

93 Véase aquí la fuerza favorable a la permanencia, a la que se refería WEBER (cit. supra).

94 Texto original compilado en el libro de Mason, L./ Rizzo, T., The French Revolution: a Document Collection, Houghton Miffin, Boston, 1999.

95 Vid. Duong, K. cit., p. 789 y WALZER, M., Regicide and Revolution: Speeches at the Trial of Louis XVI, Columbia University Press, Nueva York, 1992, p. 98.

96 SpInosa, A., Luigi XVI — L'ultimo sole di Versailles, Mondador, 2008, pp. 190-191. 
que la persona del Rey no es enjuiciable en ningún caso ${ }^{97}$, ni aún en la asunción de posibles responsabilidades paterno-filiales. De unas y otras tesis se habla, respectivamente, como nociones absolutas y nociones relativas de la inviolabilidad regia.

Se habla de nociones relativas para referirse a las que son partidarias de una interpretación sistemática y funcional de la inviolabilidad regia. En España ha sido defendida por quienes consideran que la inviolabilidad y su interpretación deben ajustarse al marco de los principios y valores constitucionales. En este sentido $^{98}$, la inviolabilidad no alcanzaría los actos privados o particulares del Monarca, dado que éstos no precisan de refrendo. Históricamente cabe sustentar esta noción en el hecho de que en el Estado constitucional y una vez se reconoce la soberanía popular. Dicho de otro modo, el poder del Monarca pasa a ser un poder constituid $0^{99}$, como habrá voces que en España comenzarán a defender ya desde las Cortes de Cádiz. Este criterio hermenéutico, nótese, no extendería las prerrogativas regias al ámbito personal, en coherencia con lo dictado por el TC español en relación con las prerrogativas parlamentarias. La interpretación de éstas no debe permitir una utilización injustificada de los privilegios (STC 243/1988; en el mismo sentido, SSTC 51/1985 y 9/1990). De algún modo se adhirió a esta idea el Consejo de Estado cuando, preguntado por la firma del Estatuto de la Corte Penal internacional y su compatibilidad con lo dispuesto en la $\mathrm{CE}^{100}$, afirmó que dicho Estatuto - que permite juzgar a Jefes de Estado por graves crímenes contra la humanidad - no choca con el artículo 56.3 CE, porque los responsables, de haberlo, serían en su caso los refrendantes y no, por tanto, el monarca. Tácitamente, nótese, parece que, según ese dictamen, el monarca sería responsable de aquellos actos que no hubieran necesitado de refrendo alguno.

Por su parte, la noción absoluta de la inviolabilidad regia es defendida desde la consideración de que ésta exonera al Monarca de todas sus actuaciones, públicas y

97 López Guerra, L., «Las funciones del Rey y la institución del refrendo», en Torres Del Moral, Antonio (dir.), Monarquía y Constitución, Colex, Madrid, 2001; GIMBERNAT, E. reafirmándose en una opinión que ya manifestó abiertamente en 1978, «La inviolabilidad del Rey», diario ELMUNDO, 13 de noviembre de 2012.

98 Portero García, L., «La responsabilidad del jefe del Estado», Revista General de Derecho, n. ${ }^{\circ} 448$ 449, 1982, pp. 1-12; Porras Ramírez, J. M., Principio democrático y función regia en la Constitución Normativa, Tecnos, 1995, pp. 175 y ss; Biglino Campos, P. «La inviolabilidad de la persona del Rey y el refrendo de sus actos», Jornadas de Derecho Parlamentario, 2001, Madrid, pp. 244 y 245; OLIVER LEón, B., Monarquía y Estado Constitucional, Tecnos, Madrid, 2002.

99 Con referencias a los escritos políticos de Emmanuel Joseph SIEYES, en tiempos de la Constitución francesa de 1791, o a Karl Loewenstein en Pueblo y Parlamento, 1922; vid. Dreier, H., «Der Ort der Souveränität», en: H. Dreier/J. HofmanN (Eds.), Parlamentarische Souveränität und technische Entwicklung, 1986, pp. 11 y ss.

100 La Ratificación por España del Estatuto de la Corte Penal Internacional (ECPI), que prevé la responsabilidad e los Jefes de Estado y de Gobierno y otras altas autoridades por, entre otros, los crímenes de genocidio y de lesa humanidad, aunque la conducta de aquéllos se hubiera limitado a la omisión de no «adop$\mathrm{t}$ [ar] todas las medidas necesarias y razonables a su alcance para prevenir o reprimir su comisión [de los delitos materialmente ejecutados por sus subordinados]» [art. 28 b) iii) ECPI], el Ministerio español de Asuntos Exteriores consultó al Consejo de Estado (C. de E.) si tal ratificación era compatible con el art. 56.3 CE que decreta la inviolabilidad del Rey. 
privadas ${ }^{101}$. En referencia a la Constitución francesa de 1791 y en su defensa de Louis XVI, el Conde de Sèze decía leer en el artículo segundo «que la persona del rey es inviolable y sagrada» y observaba también que dicha inviolabilidad estaba recogida en el texto constitucional de un modo absoluto. «No hay aquí alguna condición que la altere, ninguna excepción que la modifique, ninguna circunstancia que la disminuya; ella es, en dos palabras, inviolable y sagrada» ${ }^{102}$. A esta noción, se ha dicho ya, parece adscribirse el preámbulo de la LO 4/2014, en relación con la posibilidad de enjuiciar al monarca en los tribunales ordinarios, pero también lo ha hecho en reiteradas ocasiones la Mesa del Congreso, al afirmar que las Cortes Generales no tienen potestad para controlar la acción de la Jefatura del Estado ${ }^{103}$. Se añade también que sólo una vez abdicado podrá un monarca emérito ser acusado y juzgado, aunque sólo por actos realizados después de su abdicación.

Es oportuno señalar que las nociones absolutas han tendido a eludir pronunciarse sobre dos tipos de situaciones ante las que les resultaría difícil mantener la coherencia. Me refiero, en primer lugar, a los actos realizados por el monarca antes de su coronación. Es el caso de lo sucedido con las demandas de filiación de Ingrid Sartiau y Albert Sola, que nacieron antes incluso de que fuese designado como sucesor a titulo de Rey (1969) en el marco de la Ley de Sucesión en la Jefatura del Estado de 1947. En su recurso de apelación contra la sentencia recaída en primera instancia en su demanda de filiación paterna interpuesta por D. Albert Solá Jiménez ante la Audiencia Provincial de Madrid, afirmaba el Ministerio Fiscal que «la inviolabilidad es un concepto más amplio que al responsabilidad, no quedando sometido el Rey a la acción de la justifica en su conducta personal» ${ }^{104,105}$, sin realizar matización alguna en lo que se refiere a los términos temporales. Como es sabido, el Tribunal Supremo no tuvo ocasión de pronunciarse sobre esta cuestión.

Las nociones absolutas suelen, además, eludir pronunciarse sobre la figura de la inhabilitación, a la que la Constitución Española de 1978 se refiere muy vagamente en el artículo 59.2 CE. No establece las causas y el modo en que puede habilitarse al Rey, ni tampoco la forma en la que las Cortes Generales llegarían a proceder si se diera el caso. Tampoco la Ley Orgánica 4/ 2014 atiende a esto, toda vez que sí se

101 Torres Del Moral, A./ Gómez Sánchez, Y., Estudios sobre la Monarquía, UNED, 1995, p. 27.

102 Raymond Romain, Conde de Sèze, «Defensa de Luis XVI. Pronunciada en la Cámara de la Convención Nacional el miércoles 26 de diciembre de 1792», traducida e impresa en Cádiz a cargo de Pedro Crisóstomo Leyva, p. 21.

103 Así, entre otros, en junio de 2020.

104 Detalladamente sobre estos procedimientos y la fundamentación de las decisiones con las que fueron resueltos, véase GALERA Victoria, A. «Las demandas de filiación y la Corona. Reflexiones sobre la Inviolabilidad Regia. El acceso a la jurisdicción y la igualdad entre los hijos», Revista de Derecho UNED, n. ${ }^{\circ} 17$, 2015, pp. 319-340.

105 Sobre la admisión del recurso se pronunció el Tribunal Supremo, dado que, tras la abdicación de Juan Carlos I, en junio de 2014, y la reforma de la LOPJ mediante la L.O. 4/2014 de 11 de julio, la Audiencia Provincial de Madrid remitió todo lo actuado a la Sala de lo Civil. El Auto del Tribunal Supremo de 28 de enero de 2015, dictado por el Pleno de la Sala de lo Civil, se pronuncia sobre dicho recurso y sobre la demanda de paternidad que contra el mismo demandado había interpuesto en septiembre de 2014 D. . Ingrid J. Sartiau. 
refiere, por ejemplo, a los actos del emérito y su consorte o del Príncipe o la Princesa de Asturias, pero nada se prevé respecto de un monarca inhabilitado.

\section{LA DIFÍCIL SUPERVIVENCIA DE LAS DEMOCRACIAS CORONADAS EN EL SIGLO XXI. IMPOSIBLE SIN UNAS MÍNIMAS REFORMAS}

Advierte Häberle que, si bien la teoría del Derecho constitucional no ha prestado tanta atención los elementos emocionales o irracionales de las Constituciones como a los racionales, no por ello podemos negar que, hasta cierto punto, los Estados democráticos viven también gracias a un cierto consenso sobre lo irracional. Además de conformar discursos sobre lo racional ${ }^{106}$, todos ellos necesitan, explica Häberle, labrarse y asegurarse una cierta unidad dentro del pluralismo de opiniones, intereses y aspiraciones de lo más diverso ${ }^{107}$. Ese tipo de consensos sobre lo irracional tienen, además, importantes funciones, y probablemente sea esa una de las perspectivas desde la que se hace imprescindible acercarse a la decisión por la que en el complejo momento histórico de la transición española fuerzas políticas tan diversas aceptasen, cada una por motivos diferentes, mantener en la Jefatura de Estado a Juan Carlos I de Borbón ${ }^{108}$.

Monarquía y democracia, se dirá respecto de la Constitución Española de 1978 durante su proceso de elaboración, no son términos opuestos ${ }^{109}$. A la vista de lo expuesto, esa afirmación no es reflejo de una realidad constatada, sino una interpretación que se acoge a lo que en Derecho comparado se venía describiendo como «construcción ingeniosa» ${ }^{110}$ o, incluso, «paradoja» ${ }^{111}$ de las Jefaturas de Estado monárquicas en los sistemas democráticos. Mientras nada significativo haya llegado a alterarlas, las monarquías se mantienen en los sistemas democráticos bajo sistemas de comprensiones tácitas que no siempre se comprenden ${ }^{112}$, una vez se ha pasado ese momento inicial en que, constitucionalmente, se han considerado compatibles con el principio democrático ${ }^{113}$.

106 De Vega García, P., «Constitución y Democracia, en López Pina (ed.), La Constitución de la Monarquía Parlamentaria, FCE, México, 1983, pp.68 y ss.

107 HäBerle, P., El Estado Constitucional. Universidad Autónoma de México, 2007, México.

108 De Vega García, P., «Constitución y Democracia», en López Pina (ed.), La Constitución de la Monarquía Parlamentaria, FCE, México, 1983, pp. 68 y ss.

109 Oliver Araujo, J., «La reforma constitucional de la Corona (una propuesta radical y diez moderadas)», Revista de Derecho Político, 77/2010, pp. 15-69, p. 17.

110 Stolleis, M. Geshichte des öffentliches Rechts in Deutschland, vol. 1/ 1988, pp. 174-175; HeUN, W. «Das monarchische», cit., pp. 378-379.

111 Wynants, P. , «Trois paradoxes de la monarchie en Belgique», en La revue nouvelle. La Monarchie dans l'ètat Belge, 2002, cit., pp. 12-16.

112 Escajedo San-Epifanio, L., «La Reforma de la Sucesión a la Corona en el Reino Unido de la Gran Bretaña y Norte de Irlanda, y en los «otros Reinos» de la Commonwealth of Nations, TRC 41, 2018, pp. 213-239.

113 Boldt, H., Deutsche Staatslehre im Vormaerz, Droste Verlag, Düsseldorf, 1975, p. 15. 
Factores sociales específicos (desde las relaciones con la burguesía o el clero, o la integración y adhesión de los ciudadanos), pero también características de las personas y de sus entornos familiares son los que nos permitirían explicar cómo se han ido produciendo en cada contexto histórico y geográfico los acomodos de los monarcas a los procesos de democratización de sus naciones. Las relaciones comerciales y las influencias de algunos monarcas en las políticas exteriores han sido, asimismo, componentes que no deberían ser pasados por alto. Podríamos decir por ello, que, si bien a grandes rasgos todas las democracias coronadas guardan ciertos parecidos entre sí, la realidad de cada una de ellas sólo puede comprenderse ad hoc, haciendo muchas veces un seguimiento específico de la biografía de monarcas muy concretos.

Especialmente notable es el caso de la familia real de Bélgica ${ }^{114}$ o la relevancia de Isabel II en la actualización y fortalecimiento de la Mancomunidad de Naciones ${ }^{115}$. A su manera, también en España sería muy difícil comprender el porqué de la Monarquía actual sin las peculiares circunstancias y el modo en que acontecieron la transición y el proceso constituyente. El problema se plantea, sin embargo, cuando la institución se ve sometida a un momento crítico. Por las razones descritas, la inviolabilidad regia puede jugar un papel ambivalente, a veces reforzando y otras dejando herida de muerte a una monarquía concreta. Sin mecanismos intermedios para poder restaurar la confianza deteriorada, sólo parece posible resistir sin cambios o, por el contrario, transformar el sistema en una república.

Ese pensamiento del todo o nada está teniendo como una más de sus consecuencias el hecho de que no se explore en aquellos complementos o refuerzos que, sin mermar el actual sistema, puedan clarificarlo y hallar para los monarcas un acomodo más adecuado a los tiempos y al marco constitucional. Las monarquías contemporáneas, apunta Torres del Moral, dependen muy mucho de los reyes y príncipes, de sus hechos — que no sus palabras- . Y no poder velar por la constitucionalidad de sus hechos, es decir, la ausencia de mecanismos específicos, sólo genéricamente fortalece la institución, porque llegado el caso — por ejemplo, una crisis- no deja margen alguno para la recomposición. Como vía intermedia, si es que es cierto que buena parte del arco parlamentario aún se decanta por defender la permanencia de la institución monárquica, debería analizarse la conveniencia de abordar algunos desarrollos.

Resulta cuando menos chocante que mientras la Mesa del Congreso descarta investigar actos de un Rey, al mismo tiempo se haya extendido a la Casa Real la aplicación de la Ley 19/2013, de transparencia, acceso a la información pública y buen gobierno se aplica. ¿Qué función viene a cumplir, en ese caso, la transparencia? Consideramos que sería muy deseable una clarificación del estatuto de los

114 Monnette, P.-Y. habla de «conexión real», en Métier de Roi... ou de Reine. Familie. Etourage. Pouvoir, de A á Z, Ed. Alice, Bruselas, 2002.

115 Escajedo San-Epifanio, L.: «La Reforma de la Sucesión a la Corona en el Reino Unido de la Gran Bretaña», cit., TRC 41, 2018, pp. 213-239. 
actos privados de quien ostenta la Corona. Ello contribuiría a reforzar la seguridad jurídica dentro del sistema constitucional y, al mismo tiempo, evitaría la indefensión de aquel monarca (o monarca emérito) que como cualquier otro ciudadano desea para sí algún tipo de mecanismo con el que se tutelen su derecho a la defensa o al honor, entre otros derechos fundamentales. Flaco favor le hace a tal seguridad, dicho sea de paso, que el Preámbulo de la Ley 4/2014 haya postulado una visión tan desacertada de la inviolabilidad regia, extendiéndola a todo acto del monarca.

El mantenimiento de la irresponsabilidad del Rey, explicó Kelsen, puede ser visto como un residuo de la Monarquía absoluta, pero se sostiene en suma por el hecho de que los actos del Monarca están, en ultimo término, refrendados por ministros que, estos sí, responden ante las Cortes ${ }^{116}$. Tratar de ampliar la inviolabilidad para abarcar mucho más que los actos públicos del monarca es algo que no sólo se excede de la previsión constitucional, sino que en pleno siglo XXI no parece encontrar un sólido fundamento democrático.

Pendiente está también, en segundo lugar y último lugar, precisar en fondo y forma la figura de la inhabilitación, sea temporal sea definitiva, en modos que, nuevamente, garanticen el principio democrático y los valores recogidos en la $\mathrm{CE}$ (es decir, incluyendo los derechos fundamentales que asisten a quien, ostentando el cargo, pueda verse sometido a alguno de esos procedimientos). Aun estando el rey o reina en el cargo excluidos de justiciabilidad inmediata, nada impide articular algún tipo de procedimiento en el que, como paso previo a verse enjuiciado ante los tribunales, pueda decidirse la inhabilitación puntual o definitiva de un monarca. En todos estos casos, vaya por delante, siempre y cuando cualquier tipo de medidas de este tipo sean consideradas necesarias para preservar, en fondo y forma, el orden constitucional establecido.

$$
* * *
$$

TITLE: Royal inviolability in Comparative Perspective: historical revision and contemporary interpretations

Abstract: Recalling Garcia Pelayo, there are quite a few elements of the current democratic systems in which it would be possible to find, especially in formal terms, a certain harmonic homogeneity with their historical precedents or comparative law references. Of all of them, however, it seems that royal inviolability is one of the few -if not the only one - of the elements in which it is doubted whether the current constitutional provisions should be interpreted within the systematic framework that shelters them or whether, on the contrary, it is possible to circumvent this framework and rely on historical antecedents or comparative references to proceed with its interpretation. It would seem that, at least with respect to the royal statute, not only a certain suprapositive nature is defended, but even the supposed existence of an immovable pre-constitutional anchor, situated far from the reach of the sovereignty that resides in the people. From the perspective of Constitutional law, although without losing sight of historiography and, to a certain extent, Political psychology,

116 Kelsen, H., Teoría General del Derecho y del Estado, UNAM, 1969, pp. 334, 337. 
this work addresses the study of this phenomenon, proceeding to a historical review of royal inviolability and an analysis of contemporary interpretations of it.

Resumen: Recurriendo a García Pelayo, son bastantes los elementos de los actuales sistemas democráticos en los que cabría hallar, sobre todo en lo formal, una cierta bomogeneidad armónica con sus precedentes bistóricos o referentes de Derecho comparado. De todos ellos, sin embargo, parece que la inviolabilidad regia es uno de los pocos — sino el único- de los elementos en los que se duda si las previsiones constitucionales deben interpretarse dentro del marco sistemático que les da cobijo o si, por el contrario, cabe la posibilidad de eludir ese marco y basarse en antecedentes históricos o referentes comparados para proceder a su interpretación. Pareciera que, al menos respecto del estatuto regio, se defiende no sólo una cierta suprapositividad sino, incluso, la supuesta existencia anclaje preconstitucional inamovible, ubicado lejos del alcance de la soberanía que reside en el pueblo. Desde la perspectiva del Derecho constitucional, aunque sin perder de vista la historiografía y, hasta cierto punto, la Psicología política, este trabajo aborda el estudio de dicho fenómeno, procediendo a una revisión histórica de la inviolabilidad regia y al análisis de las interpretaciones contemporáneas de la misma.

Key words: Royal inviolability. Comparative Perspective. Crowned democracy. Parliamentary democracy. Accountability.

Palabras Clave: Inviolabilidad regia. Perspectiva comparada. Democracia coronada. Monarquía parlamentaria. Responsabilidad.

FECHA DE RECEPCIÓN: 20.06.2020

FECHA DE ACEPTACIÓN: 09.09.2020 